\title{
Personal exposures to traffic-related air pollution in three Canadian bus transit systems: the Urban Transportation Exposure Study
}

\author{
Keith Van Ryswyk ${ }^{1,2} \cdot$ Greg J. Evans $^{2} \cdot$ Ryan Kulka $^{1} \cdot$ Liu Sun $^{1} \cdot$ Kelly Sabaliauskas ${ }^{2} \cdot$ Mathieu Rouleau $^{1}$. \\ Angelos T. Anastasopolos ${ }^{1} \cdot$ Lance Wallace ${ }^{3} \cdot$ Scott Weichenthal ${ }^{1,4}$
}

Received: 20 January 2020 / Revised: 20 May 2020 / Accepted: 5 June 2020 / Published online: 16 July 2020

(c) The Author(s) 2020. This article is published with open access

\begin{abstract}
Background Exposure to traffic-related air pollution (TRAP) is associated with increased incidence of several cardiopulmonary diseases. The elevated TRAP exposures of commuting environments can result in significant contributions to daily exposures.

Objectives To assess the personal TRAP exposures (UFPs, BC, $\mathrm{PM}_{2.5}$, and $\mathrm{PM}_{10}$ ) of the bus transit systems of Toronto, Ottawa, and Vancouver, Canada. Personal exposure models estimated the contribution of bus commuting to daily TRAP exposures. Associations between bus type and riding exposures and bus stop/station type and waiting exposures were estimated.

Results Bus commuting (4.6\% of the day) contributed $\sim 59 \%(\mathrm{SD}=15 \%), 60 \%(\mathrm{SD}=20 \%)$, and $57 \%(\mathrm{SD}=18 \%)$ of daily $\mathrm{PM}_{2.5}-\mathrm{Ba}$ and $70 \%(\mathrm{SD}=19 \%), 64 \%(\mathrm{SD}=15 \%)$, and $70 \%(\mathrm{SD}=15 \%)$ of daily $\mathrm{PM}_{2.5}-\mathrm{Fe}$, in Toronto, Ottawa, and Vancouver, respectively. Enclosed bus stations were found to be hotspots of $\mathrm{PM}_{2.5}$ and $\mathrm{BC}$. Buses with diesel particulate filters (DPFs) and hybrid diesel/electric propulsion were found to have significantly lower in-bus $\mathrm{PM}_{2.5}$, UFP, and BC relative to 1983-2003 diesel buses in each city with the exception of UFP in Vancouver.

Significance Personal exposures for traffic-related air pollutants were assessed for three Canadian bus transit systems. In each system, bus commuting was estimated to contribute significantly toward daily exposures of fine-fraction $\mathrm{Ba}$ and $\mathrm{Fe}$ as well as BC. Exposures while riding were associated with bus type for several pollutants in each city. These associations suggest the use of hybrid diesel/electric buses equipped with diesel particulate filters have improved air quality for riders.
\end{abstract}

Keywords Personal exposure $\cdot$ Bus transit $\cdot \mathrm{UFP} \cdot \mathrm{PM}_{2.5} \cdot \mathrm{BC} \cdot$ Metals

Supplementary information The online version of this article (https:// doi.org/10.1038/s41370-020-0242-2) contains supplementary material, which is available to authorized users.

Keith Van Ryswyk

Keith.VanRyswyk@canada.ca

1 Air Health Science Division, Health Canada, Ottawa, ON K1A 0K9, Canada

2 Department of Chemical Engineering and Applied Chemistry, University of Toronto, Toronto, ON, Canada

3 Santa Rosa, CA 5409, USA

4 Department of Epidemiology, Biostatistics, and Occupational Health, McGill University, Montreal, QC H3A 1A2, Canada

\section{Introduction}

Traffic-related air pollution (TRAP) is ubiquitous in urban environments and constitutes a significant burden on public health. Exposure to TRAP has been found to increase the incidence of several cardiopulmonary diseases [1-4], cancers [5-8], as well as type II diabetes [9], and is related to neurotoxicity $[10,11]$. In North America, the transportation sector is estimated to account for $32 \%$ of total fine particulate matter $\left(\mathrm{PM}_{2.5}\right)$ mortality [12]. This evidence has led to the adoption of increasingly stringent regulations resulting in reductions of engine and vehicle emissions and regulated air pollutants [13]. In Canada, the reduction of traffic-related $\mathrm{PM}_{2.5}$ emissions, as reflected in Canadian air pollutant emission inventories, has likely contributed to a $\sim 25 \%$ decrease in Canadian population-weighted mean $\mathrm{PM}_{2.5}$ concentration from 2000 to 2011 [14]. 
Personal exposures to TRAP in commuting environments is a research priority. While commuting represents $\sim 5 \%$ of a Canadian's day [15], this microenvironment can represent a larger proportion of daily exposure to trafficrelated air pollutants [16-18]. The characterization of air pollution in urban transport environments can help refine air pollution exposure estimates as well as inform air quality policy. The Urban Transportation Exposure Study (UTES) was designed to assess TRAP exposures in Canadian commuting environments. Results from the subway/metro [18], and private vehicle [19] components of UTES are published elsewhere. This paper presents an air pollution exposure assessment for the public bus transit systems of Toronto, Ottawa, and Vancouver, Canada.

Public bus transit is used by $12.2 \%$ of Canadians and their bus commute represents an average of $66 \mathrm{~min}(4.6 \%)$ of their day [20]. While subways are almost exclusively electric propulsion and private vehicles predominantly use gasoline, public bus transit is extensively diesel propulsion. Diesel exhaust is a known source of black carbon (BC) and ultrafine particles (UFPs) and has been designated carcinogenic [21]. Further, BC may play a role in the health effects associated with TRAP [22]. Air pollution exposure data specific to this staple of public transit are valuable for air pollution risk assessment and management.

Several heavy-duty diesel engine exhaust emission standards have been adopted in Canada. For example, emission standards introduced in 2004 targeted the reduction of NOx emissions, which were met mainly through the use of exhaust gas recirculation. Exhaust emission standards for diesel engines of model year 2007 and later are ten times lower than previous limits for $\mathrm{PM}_{2.5}$ (On-Road Vehicle and Engine Emission Regulations, SOR/2003-2). This drastic reduction in the PM emission limit in 2007 coincided with the availability of ultra-low sulfur diesel fuel starting in 2006 (Sulphur in Diesel Fuel Regulations, SOR/2002/254) which enabled the use of efficient exhaust after-treatment devices, notably diesel particulate filters (DPFs). these measures to decrease exhaust emissions have reduced ambient air concentrations, their impact on in-bus exposures has not been studied.

Non-exhaust sources of TRAP are a growing concern. A review of the epidemiological evidence of the health effects of non-exhaust particles suggests that it has both short and long term health effects [23]. As well data from long term monitoring at a downtown site in Toronto have indicated that non-exhaust emissions are an increasing component of TRAP [24]. In the context of bus transit environments, they are particularly relevant due to the brake and wheel wear of these heavy vehicles. Sources of non-exhaust emissions include the degradation of roads, brakes, and tires and are typically represented by trace metals [25]. Several trace metals have been associated with increased risk of disease. Exposure to fine-fraction trace elements have been associated with cardiopulmonary hospitalizations and mortality [26-28] and lung cancer [29]. While research on identifying the health burden of fine-fraction trace elements continues, so too should work on estimating the contribution of commuting to the daily exposure of these pollutants. Such evidence is valuable toward informing personal exposure modeling and mitigation.

This work has several research objectives. The first was to characterize the traffic-related air pollutants of nitrogen dioxide $\left(\mathrm{NO}_{2}\right)$, UFPs, $\mathrm{BC}, \mathrm{PM}_{2.5}$, coarse particulate matter $\left(\mathrm{PM}_{10}\right)$, and the elemental content of $\mathrm{PM}_{2.5}$ and $\mathrm{PM}_{10}$ for the bus transit systems of Toronto, Ottawa, and Vancouver, Canada. The second was to estimate the contribution of bus commuting to overall daily TRAP exposures. The third was to estimate the potential of bus stations to represent TRAP exposure hotspots by comparing their exposures to that of bus stops. Fourth: the simulation of air quality interventions on the daily means of our waiting and riding exposure data. To this end, our estimates of lower waiting exposures at bus stops (relative to bus stations) were used to estimate the impact of air quality interventions designed to reduce bus station concentrations to that of bus stops. Also, we used our estimates of lower riding exposures in hybrid diesel/ electric buses (relative to 1983-2003 buses) to estimate the impact of the replacement of 1983-2003 buses with hybrid diesel/electric buses.

\section{Methods}

\section{Data collection}

Air pollution exposure data were collected in the public bus transit systems of Toronto and Ottawa, Ontario for three weeks in the summer of 2010 and the winter of 2011 and in Vancouver, British Columbia in the winter and summer of 2013. Data were collected during the peak commuting hours of 7-10 a.m. and 3-6 p.m. of each weekday. During each 3-h sampling session, three researchers, assigned to separate areas of the city, carried equipment in personal sampling backpacks (Fig. 1). Bus routes reflecting high ridership and the geographic extent of the network were selected to best reflect exposures for the majority of bus commuters. While sampling each bus route, researchers disembarked at bus stops/stations at regular intervals to ensure the collection of both waiting and riding exposures. This also ensured data collection for a wide variety of bus stop/station types and bus make years and propulsion types. Geographic location data were collected using a global 
Fig. 1 Personal air monitoring set up and geographical coverage of sampled routes in Toronto, Ontario; Ottawa,

Ontario; and Vancouver, British Columbia.

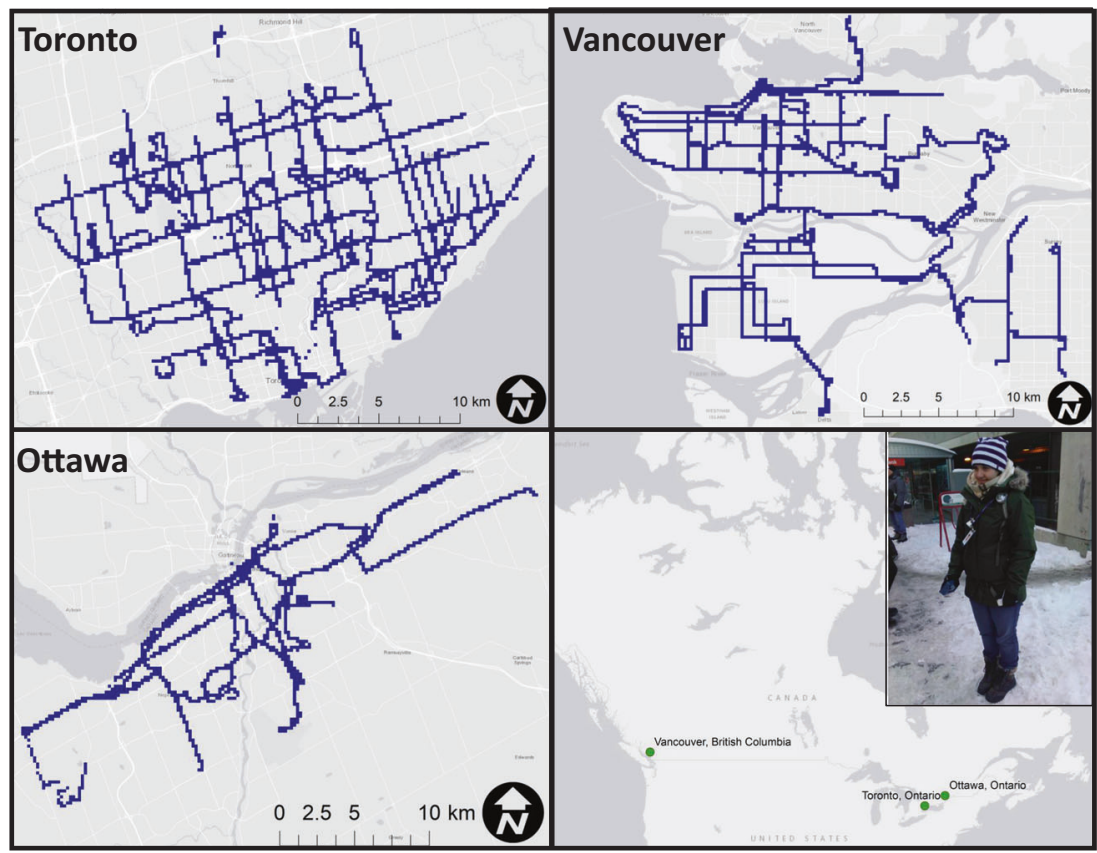

position recorder (GlobalSat DG-100). Digital voice recordings (DVR) were used to identify periods of riding and waiting as well as bus and bus stop IDs.

Continuous data were recorded in 1-s intervals and averaged over each session of waiting and riding. This resulted in a series of data points alternating between waiting and riding over each 3-h period. Sampling inlets for the air pollution monitors were positioned in the breathing zone. Throughout each 3-h monitoring session, $\mathrm{PM}_{2.5}$, UFPs, and $\mathrm{BC}$ were measured continuously with electronic devices. The internal clocks of all continuous instruments, including GPS data and DVRs, were synchronized to the researcher's computers on a daily basis. All were merged at 1-s intervals. Continuous data were then averaged over each waiting and riding session. Further detail on the continuous air pollution monitoring instruments and QAQC are provided in Supplementary section 1.1. Filter-based $\mathrm{PM}_{2.5}$ and $\mathrm{PM}_{10}$ samples were collected concurrently with the continuous data. Each sample represented the $30 \mathrm{~h}$ of sampling conducted by a researcher each week for a total of $18 \mathrm{PM}_{2.5}$ and $\mathrm{PM}_{10}$ samples for each city. Further detail on the integrated $\mathrm{PM}_{2.5}$ and $\mathrm{PM}_{10}$ methods can be found in Supplementary section 1.2.

\section{Estimating the contribution of bus commuting to daily exposures}

Microenvironmental models combining bus and ambient exposure data were created to estimate the contribution of bus commuting to overall daily exposures of $\mathrm{PM}_{2.5}$ and $\mathrm{PM}_{2.5}$-elements as well as $\mathrm{BC}$ and UFP. Since these models pertain to the impact of commuting, their context applies only to weekdays. The microenvironmental model for $\mathrm{PM}_{2.5}$ and fine-fraction elements combined the personal bus commuting exposure data collected in this study with fixed-site ambient monitoring data and a correction factor to account for the differences in $\mathrm{PM}_{2.5}$ sampling methods. The microenvironmental model for BC and UFP differed from the $\mathrm{PM}_{2.5}$ model. With the high temporal resolution of the BC and UFP data collected in this study, exposures specific to riding and waiting were calculated. Also, in place of available ambient data for UFP and BC, estimates were made for three ("low", "moderate", and "high") ambient conditions. Both approaches used the figure of $66 \mathrm{~min}$ as the amount of time spent in the bus environment [20].

For estimating the percent contribution of bus commuting to weekday $\mathrm{PM}_{2.5}$ and $\mathrm{PM}_{2.5}$-elemental exposures, ambient (non-commuting) exposures were represented by data downloaded from the National Air Pollution Surveillance (NAPS) network operated by Environment and Climate Change Canada (ECCC). ECCC conducts the routine collection of 24-h gravimetric $\mathrm{PM}_{2.5}$ for several stations across Canada every 3 days. One NAPS site in each city (Toronto, Ottawa, and Vancouver) collected gravimetric data for the study period. NAPS data collected during and within 2 weeks of each six sampling sessions (three cities $\times$ two seasonal sampling periods) were downloaded to represent ambient levels of $\mathrm{PM}_{2.5}$ and its elemental composition. These data were then averaged to produce mean levels for each city and season. Elements which were measured to be above detection for $>50 \%$ of 
samples in both the bus sampling and ambient environments were included in the analysis along with $\mathrm{PM}_{2.5}$ itself. Bus commuting exposures were represented by the 18 integrated $\mathrm{PM}_{2.5}$ samples collected in each city (Supplementary section 1.2). The percent contribution of bus commuting to overall $\mathrm{PM}_{2.5}$ components (mass and elemental concentration) was calculated with each bus sample and its corresponding ambient seasonal mean (Eq. 1). $\mathrm{G}_{\text {busPM2.5ijk }}$ represents the estimated contribution of a typical 66-min bus commute to $\mathrm{PM}_{2.5}$ exposure for sample $i, \mathrm{PM}_{2.5}$ component $j$, and season $k$. $X_{\text {busPM2.5ij }}$ represents the concentration of $\mathrm{PM}_{2.5}$ component $j$ for sample $i, X_{\mathrm{AmbientPM} 2.5 \mathrm{jk}}$ is the mean concentration of $\mathrm{PM}_{2.5}$ component $j$ for season $k$, and $A_{\text {PEM:Dichot }}$ represents the correction factor for the $11 \%$ positive bias of the PEM, relative to the dichotomous sampler used by NAPS [30]. The mean and standard deviation of the resulting values $(n=18)$ were then calculated for each city.

$$
\begin{aligned}
& G_{b u s P M_{2.5 j k}}=
\end{aligned}
$$

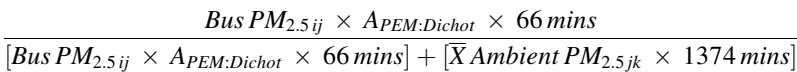

The percent contribution of bus commuting to overall daily exposures of BC and UFP was estimated using the continuously monitored BC and UFP data. As with the $\mathrm{PM}_{2.5}$ analysis, the figure of $66 \mathrm{~min}$ was used as the time spent on buses, however, a weighted average between time spent waiting at bus stations (16 min - based on mean waiting time (Supplementary Table S2)) and time spent on buses $(50 \mathrm{~min})$ was calculated to represent bus exposure. Ambient data from NAPS for BC and UFP were largely unavailable for these cities during these time periods. Therefore, the percent contribution of bus commuting for overall daily BC and UFP exposure was calculated for three scenarios of mean ambient (non-commuting) exposure. For $\mathrm{BC}$, these were $0.5,1.0$, and $1.5 \mu \mathrm{g} / \mathrm{m}^{3}$ and 5,10 , and $15 \times$ $10^{3} \mathrm{pts} / \mathrm{cm}^{3}$ for UFP. These values of "low", "moderate", and "high" non-commuting exposures were selected to represent the variation possible in consideration of how much time a person spends indoors and in close proximity to busy roads. The microenvironmental model for estimating the percent contribution of bus commuting to daily exposure to UFP and BC is presented in Eq. (2) where $G_{\text {bus }}$ ijk represents the estimated contribution of a typical 66-min bus commute for sampling day $i$, pollutant $j$, and ambient condition $k$. $X_{\text {waiting ij }}$ represents the mean bus stop (waiting) exposure for day $i$ and pollutant $j, X_{\text {riding ij }}$ represents the mean in-bus (riding) exposure for day $i$ and pollutant $j$, and Ambient $_{\mathrm{j} k}$ represents the mean pollutant $j$ for ambient scenario $k$ ("low" "moderate", or "high"). The mean and standard deviation of the resulting values were then calculated for each city $(n=30)$.

$$
\begin{aligned}
& G_{b u s s_{j k}}= \\
& \frac{\left[\bar{X}_{\text {waiting }_{i j}} \times 16 \text { mins }\right]+\left[\bar{X}_{\text {riding }_{i j}} \times 50 \text { mins }\right]}{\left[\bar{X}_{\text {waiting }_{i j}} \times 16 \text { mins }\right]+\left[\bar{X}_{\text {riding }_{i j}} \times 50 \text { mins }\right]+\left[\bar{X} \text { Ambient }_{j k} \times 1374 \text { mins }\right]} \\
& \begin{array}{l}
\text { Impact of bus stop type and bus type on } \mathrm{PM}_{2.5} \text {, UFP, } \\
\text { and } \mathrm{BC} \text { exposures }
\end{array}
\end{aligned}
$$

Upon boarding a bus or disembarking at a stop, DVR recordings were made of each bus and stop ID. Bus IDs were cross-referenced with transit authority fleet data on manufacture year and propulsion type. This information was used to classify each bus type as 1983-2003 diesel, 2004-2006 diesel, 2007- diesel, hybrid diesel/electric, or electric. This classification scheme reflects the adoption of heavy-duty diesel engine exhaust emission standards in Canada, which have generally mirrored those from the United States. The 1983-2003 diesel bus category includes older technology engines that meet less stringent emission standards. The 2004-2006 category represents buses designed to meet 2004 emission standards. The post 2007 category represents buses, which feature DPFs. The hybrid diesel/electric propulsion systems are based on different engine characteristics, operating regimes, and fuel consumption profiles compared with conventional diesel engines. They are considered a distinct class, irrespective of model year. Electric buses are also a distinct class, irrespective of model year, as they do not emit exhaust emissions. Bus stops were classed as "bus stop" (street level outdoor stop), "outdoor bus station" (street level outdoor station serving as a hub for several bus routes), and "enclosed bus station" (indoor/below grade station serving as a hub for several bus routes). GPS data of "waiting" sessions were plotted in ArcGIS to confirm bus stop classifications.

Multivariate linear mixed models were developed to estimate differences in exposure between each class of bus stop and bus type and a referent class. As these conditions changed throughout each 3-h monitoring period, this analysis was only possible with continuously monitored pollutants $\left(\mathrm{PM}_{2.5}\right.$, UFP, and $\left.\mathrm{BC}\right)$. Waiting exposure data were used to test for a significant difference between exposures at bus stations (outdoor and enclosed) and bus stops (the referent class). Riding exposure data were used to test for a significant difference between the exposures of the various bus types (2004-2006 diesels, 2007- diesels, hybrid diesel/ electric, and electric) and 1983-2003 diesels (the referent class). In total, nine models were developed to estimate the effect of bus stop and bus type (one for each combination of city and continuously monitored pollutant). The multivariate mixed-effects linear regression models 
included adjustment for confounders in order to isolate the effect of the main predictor (bus stop type and bus type). A directed acyclic graph (DAG) was used to inform the selection of confounding variables. Specifically, we identified the minimal sufficient adjustment set of variables for estimating the effect of bus type on riding exposures and bus stop type on waiting exposures. Several types of land use (commercial, industrial, residential, open space, and parks) and road types (local roads, major roads, and highways) were identified as potential confounders (Supplementary Fig. S2). Controlling for factors of land-use and road network information was essential as they can affect air pollutants in bus transit [31, 32]. Each confounder was represented as the quantity within a $500 \mathrm{~m}$ buffer. The DAG was built using DAGitty version 3.0 (http://www.dagitty. net/). Estimates of the relationship between bus type and bus stop type and exposure levels were calculated using the "proc mixed" procedure in SAS EG 5.1 (SAS Institute Inc., Cary, NC, USA). An autoregressive covariance structure $\left(\mathrm{AR}_{1}\right)$ was used to account for the lack of independence within the repeated measurements within each 3 -h session (Eq. 3).

$$
Y_{i j}=\alpha+\beta_{1} X_{1}+\beta_{2} X_{2}+\ldots+\beta_{n} X_{n}+b_{i}+\varepsilon_{i j}
$$

Here, $Y_{i j}$ is the natural logarithm for $\mathrm{PM}_{2.5}$, UFP, or BC for riding/waiting session $i$, on day $j, \alpha$ is the regression intercept, $\beta_{1}$ is the effect of bus stop/bus type $\left(X_{1}\right)$ on $\mathrm{Y}, \beta_{2}$ is the effect of the first confounder of $n$ confounders, $b_{i}$ is the random effect for propulsion/stop type and $\varepsilon_{i j}$ is the random error. Effects of influential points were assessed by calculating Cook's distances. Residual plots were assessed for normality using the Shapiro-Wilk statistic. Predictor parameter estimates and $95 \%$ confidence intervals were exponentiated to provide estimates of percent change in exposure. Significant differences between outdoor and enclosed bus stations and bus stops were expressed as percent increases in exposure. Significant differences in exposures between the 2004-2006 diesels, 2007-diesels, hybrid diesel/electric, and electric bus types and the referent 1983-2003 bus type were expressed as percent decreases.

\section{Estimating the impact of simulated bus fleet renewal and bus station air quality interventions}

Results of the mixed model analyses were applied to simulate the impact of interventions designed to improve waiting and riding exposures of $\mathrm{PM}_{2.5}$, UFP, and $\mathrm{BC}$. This analysis combined the effect size of lower waiting concentrations at bus stops and riding concentrations in hybrid diesel/electric buses with the frequency in which they were encountered during sampling. For waiting exposures, mixed model estimates of higher exposures for outdoor and enclosed bus stations (relative to bus stops) were used to estimate the impact of improving bus station air quality. For riding exposures, mixed model estimates of lower exposures for hybrid diesel/electric buses (relative to the 1983-2003 class) were used to estimate the impact of bus fleet changeover (replacement of 1983-2003 buses with diesel hybrid/electric). Daily means of waiting and riding concentrations were calculated before and after the application of air quality improvements. Percent reduction of waiting and riding exposures were then calculated for each daily mean. The mean and standard deviation of the resulting values $(n=30)$ were then presented for each.

\section{Results}

\section{Data collection and TRAP exposure levels}

Technicians collected exposure data for $~ 900$ (Toronto), 1700 (Ottawa), and 1400 (Vancouver) riding and waiting sessions (Supplementary Table S2). Riding sessions lasted an average of 17,8 , and $14 \mathrm{~min}$ in Toronto, Ottawa, and Vancouver, respectively. Waiting sessions were on average $\sim 8 \mathrm{~min}$ in all three cities. A description of TRAP exposure levels with breakdowns by city and season (Supplementary Table S3), waiting/riding (Supplementary Table S4), bus type (Supplementary Table S5), and busstop type (Supplementary Table S6) can be found in section 2 of the Supplementary. Results of the $\mathrm{PM}_{2.5}$ and $\mathrm{PM}_{10}$ integrated samples are presented in Supplementary Table S7.

\section{Contribution of bus commuting to daily exposure of $\mathbf{P M}_{2.5}$ mass, its elemental constituents, $\mathrm{BC}$, and UFP}

The gravimetric $\mathrm{PM}_{2.5}$ bus commuting exposures were combined with central site ambient data using a personal exposure model to estimate the percent contribution of bus commuting towards mean daily exposures. A total of 21 central site ambient samples were available in each city and 18,17 , and 14 elements met the inclusion criteria for this analysis for Toronto, Ottawa, and Vancouver, respectively. Descriptive statistics for bus and ambient exposure for $\mathrm{PM}_{2.5}$ and these elemental constituents are presented in Supplementary Tables S8A (Toronto), S8B (Ottawa), and S8C (Vancouver). A summary of the percent contribution estimates are presented in Table 1. A typical $66 \mathrm{~min}$ bus commute (4.6\% of the day) was estimated to contribute $6 \%$ $(\mathrm{SD}=2 \%)$ (Toronto), $13 \%(\mathrm{SD}=10 \%)$ (Ottawa), and $11 \%$ $(\mathrm{SD}=4 \%)$ (Vancouver) of weekday $\mathrm{PM}_{2.5}$ exposure. Daily exposure to several elements were highly influenced by bus commuting. Time spent bus commuting was estimated to 
contribute $59 \%(\mathrm{SD}=15 \%)$ (Toronto), 60\% $(\mathrm{SD}=20 \%)$ (Ottawa), and $57 \%(\mathrm{SD}=18 \%)$ (Vancouver) of daily exposure to fine-fraction $\mathrm{Ba}$, and $70 \%(\mathrm{SD}=19 \%$ ) (Toronto), $64 \%(\mathrm{SD}=15 \%)($ Ottawa), and $70 \%(\mathrm{SD}=15 \%)$ (Vancouver) of daily exposure to fine-fraction Fe. Contributions of over $25 \%$ in each city were also noted for $\mathrm{Al}$, $\mathrm{Cu}$, and $\mathrm{Ti}$.

Table 1 Contribution of bus commute to daily exposure of $\mathrm{PM}_{2.5}$ mass and elements.

\begin{tabular}{|c|c|c|c|}
\hline \multirow[t]{2}{*}{ Element } & \multicolumn{3}{|c|}{ Mean (SD) $\%$ contribution $^{a}$} \\
\hline & Toronto $(n=18)$ & Ottawa $(n=18)$ & Vancouver $(n=17)$ \\
\hline $\mathrm{PM}_{2.5}$ & $6(2)$ & $13(10)$ & $11(4)$ \\
\hline $\mathrm{Al}$ & $26(11)$ & $32(23)$ & $38(15)$ \\
\hline As & 7 (3) & $5(3)$ & $8(2)$ \\
\hline $\mathrm{Ba}$ & $59(15)$ & $60(20)$ & $57(18)$ \\
\hline $\mathrm{Cd}$ & $8(7)$ & $10(9)$ & - \\
\hline $\mathrm{Cr}$ & $27(21)$ & 19 (18) & - \\
\hline Co & - & - & $21(9)$ \\
\hline $\mathrm{Cu}$ & $30(15)$ & $37(9)$ & $32(7)$ \\
\hline $\mathrm{Fe}$ & $70(19)$ & $64(15)$ & $70(15)$ \\
\hline $\mathrm{Mn}$ & $27(14)$ & $23(13)$ & $18(9)$ \\
\hline Mo & $17(12)$ & $24(7)$ & $22(6)$ \\
\hline $\mathrm{Ni}$ & $15(11)$ & $22(16)$ & $14(9)$ \\
\hline $\mathrm{Pb}$ & $12(6)$ & $10(5)$ & $18(13)$ \\
\hline $\mathrm{Sb}$ & $12(4)$ & $10(6)$ & $36(10)$ \\
\hline $\mathrm{Se}$ & $4(2)$ & - & - \\
\hline $\mathrm{Sn}$ & $17(4)$ & $19(8)$ & - \\
\hline $\mathrm{Sr}$ & $20(9)$ & $26(15)$ & $24(9)$ \\
\hline $\mathrm{Ti}$ & 39 (14) & 41 (19) & - \\
\hline $\mathrm{V}$ & $6(2)$ & $8(5)$ & $13(6)$ \\
\hline $\mathrm{Zn}$ & $10(9)$ & $12(11)$ & $8(2)$ \\
\hline
\end{tabular}

Full table can be found in Supplementary (S8A, B, C).

${ }^{\mathrm{a}}$ Percent contribution of $66-\mathrm{min}$ bus commute ( $4.6 \%$ of day) to overall daily exposure (Eq. 1).

Table 2 Percent contribution of bus commute to daily UFP and $\mathrm{BC}$ for a range of ambient levels.
Estimates of the contribution of bus commuting to daily $\mathrm{BC}$ and UFP exposure are presented in Table 2. Bus commuting contributed $7.1-8.9 \%$ of overall daily UFP exposures in the "moderate" ambient (non-commuting exposure) condition of $5 \times 10^{3} \mathrm{pts} / \mathrm{cm}^{3}$. For BC, bus commuting contributed $19.1-23.0 \%$ of daily $\mathrm{BC}$ exposures in the "low" ambient (non-commuting) exposure scenario of $0.5 \mu \mathrm{g} / \mathrm{m}^{3}$.

\section{Effect of bus stop type on waiting exposures of $\mathrm{PM}_{2.5}, \mathrm{UFP}$, and $\mathrm{BC}$}

The \% increases in $\mathrm{PM}_{2.5}$, UFP, and $\mathrm{BC}$ exposure for outdoor and enclosed bus stations, relative to bus stops, are presented in Table 3. In Toronto, $\mathrm{PM}_{2.5}$ levels for outdoor bus stations were $55 \%$ (95\% CI: 39-73\%) higher than bus stops while enclosed bus stations were 79\% (95\% CI: 61-100\%) higher. UFP levels were slightly higher for outdoor bus stations in Ottawa (25\% 95\% CI: 15-37\%) relative to bus stops but this difference was not seen for enclosed bus stations. In Toronto, UFP levels were counterintuitively lower at bus stations relative to bus stops, both outdoor and enclosed. In Toronto and Ottawa, increases in $\mathrm{BC}$ levels were noted at outdoor bus stations with further increases at enclosed bus stations. BC exposures at outdoor bus stations were significantly higher than bus stops in Toronto (64\%, 95\% CI: $30-107 \%)$ and Ottawa (27\% 95\% CI: $14-42 \%)$. As well, enclosed bus stations showed further increases in BC levels as they were $112 \%(95 \% \mathrm{CI}$ : 66-172\%) higher than bus stops in Toronto and 56\% (95\% CI: 22-99\%) higher in Ottawa. No enclosed bus stations were encountered in Vancouver and only a small sample of bus station data were collected.

\section{Effect of bus type on riding exposures of $\mathrm{PM}_{2.5}$, UFP, and $B C$}

Percent decreases in $\mathrm{PM}_{2.5}$, UFP, and $\mathrm{BC}$ exposures by bus type relative to the referent condition (1983-2003 diesel)

\begin{tabular}{|c|c|c|c|c|c|c|}
\hline \multirow[t]{2}{*}{ Pollutant } & \multirow[t]{2}{*}{ City } & \multicolumn{2}{|c|}{$\begin{array}{l}\text { Mean daily } \\
\text { concentration (SD) }\end{array}$} & \multicolumn{3}{|c|}{$\begin{array}{l}\text { Mean } \% \text { contribution by ambient } \\
\text { condition }(\mathrm{SD})^{\mathrm{a}}\end{array}$} \\
\hline & & Riding & Waiting & Low & Moderate & High \\
\hline Ultrafine & Toronto & $16.2(4.1)$ & $24.5(7.5)$ & $14.7(3.3)$ & 8.0 (1.9) & $5.5(1.3)$ \\
\hline particles & Ottawa & $18.9(8.5)$ & $26.9(15.5)$ & $16.2(6.4)$ & 8.9 (3.9) & $6.2(2.8)$ \\
\hline$\left(10^{3} \mathrm{pts} / \mathrm{cm}^{3}\right)$ & Vancouver & $16.1(12.1)$ & $18.4(14.2)$ & $13.0(8.6)$ & $7.1(5.0)$ & $4.9(3.5)$ \\
\hline Black & Toronto & $3.1(2.0)$ & $4.6(4.3)$ & $23.0(11.9)$ & $13.5(8.0)$ & $9.6(6.0)$ \\
\hline Carbon & Ottawa & $2.6(1.4)$ & $2.8(1.5)$ & $19.4(9.0)$ & $11.0(5.5)$ & $7.7(4.0)$ \\
\hline$\left(\mu \mathrm{g} / \mathrm{m}^{3}\right)$ & Vancouver & $2.6(0.6)$ & $2.0(0.6)$ & $19.1(3.5)$ & $10.6(2.1)$ & $7.3(1.5)$ \\
\hline
\end{tabular}

Calculated for each daily mean waiting and riding $(n=30)$. Low ambient: $5 \times 10^{3} \mathrm{pts} / \mathrm{cm}^{3}$ UFP and $0.5 \mu \mathrm{g} / \mathrm{m}^{3}$ BC; moderate ambient: $10 \times 10^{3} \mathrm{pts} / \mathrm{cm}^{3}$ UFP and $1.0 \mu \mathrm{g} / \mathrm{m}^{3} \mathrm{BC}$; high ambient: $15 \times 103 \mathrm{pts} / \mathrm{cm}^{3}$ UFP and $1.5 \mu \mathrm{g} / \mathrm{m}^{3} \mathrm{BC}$.

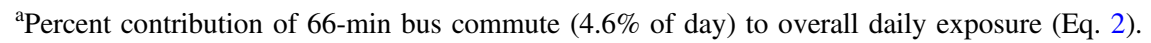




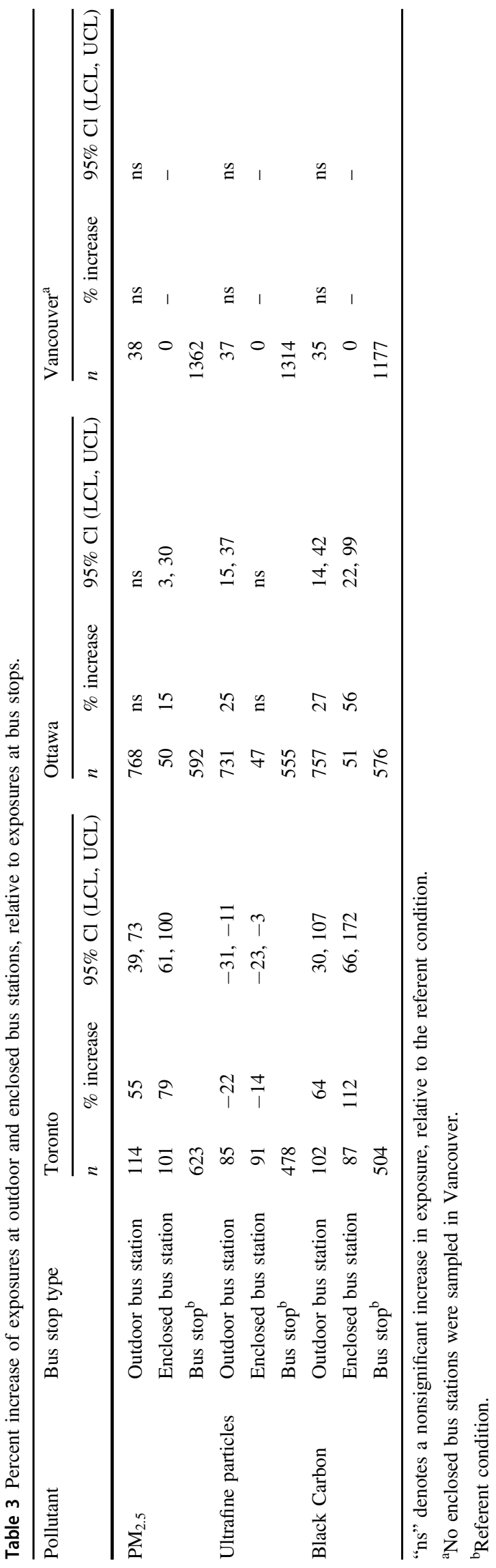

are presented in Table 4. Across the nine groups defined by TRAP pollutant and city, both the 'hybrid electric/diesel' and '2007- diesel' classes were found to have the most cases of $\%$ decreases in exposure relative to the "1983-2003" class. Exposures on hybrid electric/diesel buses were significantly lower than the referent group in $\mathrm{PM}_{2.5}$, UFP, and BC in all three cities with the exception of UFPs in Vancouver. The 2007- diesel buses were associated with lower $\mathrm{PM}_{2.5}$ in Toronto $(38 \%, 95 \% \mathrm{CI} ; 29-46 \%)$ and Vancouver $(40 \%, 95 \% \mathrm{CI} ; 36-45 \%)$, and lower UFP in Toronto (40\%, 95\% CI; 27-50\%). The 2007- diesel buses also had significantly lower BC levels in all three cities (Toronto: 38\%, 95\% CI; 23-50\%), Ottawa: (24\%, 95\% CI; 16-32\%), and Vancouver: (20\%, 95\% CI; 11-29\%)). The 2004-2006 diesel buses were estimated to have lower $\mathrm{PM}_{2.5}$ in Vancouver $(18 \%, 95 \% \mathrm{CI}$; 9-27\%), lower UFP in Toronto $(30 \%, 95 \% \mathrm{CI} ; 17-40 \%)$ and counterintuitively higher UFP in Vancouver $(-22 \%, 95 \% \mathrm{CI} ;-42$ to $-5 \%)$.

\section{Estimated impact of bus station air quality interventions}

As per the results presented in Table 3, both outdoor and enclosed bus stations in Toronto had significantly higher $\mathrm{PM}_{2.5}$ and $\mathrm{BC}$ exposures. In Ottawa, outdoor and enclosed bus stations had significantly higher BC exposures while only outdoor bus stations had higher UFPs and enclosed stations had higher $\mathrm{PM}_{2.5}$. The counterintuitively lower UFP exposures at Toronto bus stations were not applied in this analysis. The impact of the simulated reduction of bus station exposures to that of bus stops on the mean daily waiting exposures measured in this study are presented in Table 5. In Toronto, overall waiting $\mathrm{PM}_{2.5}$ exposures were reduced by $13 \%(\mathrm{SD}=7.5 \%)$ and $\mathrm{BC}$ was reduced by $11.4 \%(\mathrm{SD}=2.6 \%)$. In Ottawa, waiting exposures were reduced for $\mathrm{PM}_{2.5} \quad($ mean $=0.5 \%, \quad \mathrm{SD}=0.85 \%)$, UFP $($ mean $=11.4 \%, \quad \mathrm{SD}=2.6 \%)$, and $\mathrm{BC} \quad($ mean $=14.1 \%$, $\mathrm{SD}=4.1 \%$ ).

\section{Estimated impact of bus fleet renewal}

The simulated impact on the daily mean riding exposures measured in this study by the replacement of 1983-2003 buses with hybrid diesel/electric buses is presented in Table 6. The hybrid diesel/electric class was used for this simulation as it was found to have significantly lower exposures in eight of the nine combinations of city and pollutant. In our sample, the 1983-2003 bus class was encountered 15\% (Toronto), 27\% (Ottawa), and 39\% (Vancouver) of the time researchers boarded a bus. Riding exposures were reduced by an average of $6.3 \%(\mathrm{SD}=$ $5.2 \%), 6.6 \%(\mathrm{SD}=4.8 \%)$, and $17.6 \%(\mathrm{SD}=7.5 \%)$ for $\mathrm{PM}_{2.5}$ and $4.6 \%(\mathrm{SD}=4.0 \%), 12.7 \% \quad(\mathrm{SD}=8.9 \%)$, and 


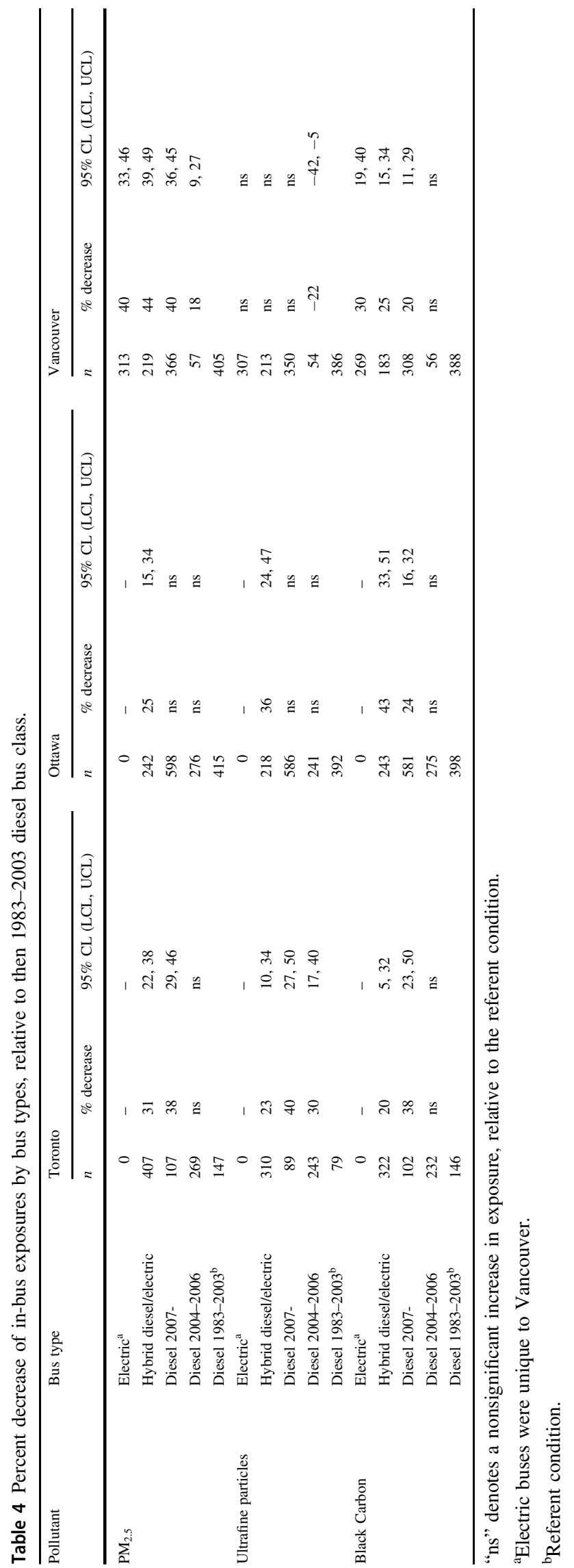

9.9\% $(\mathrm{SD}=4.1 \%)$ for $\mathrm{BC}$ in Toronto, Ottawa, and Vancouver, respectively. Mean percent reductions for riding UFP exposures were $3.6 \%(\mathrm{SD}=3.1 \%)$ in Toronto and $10.7 \%(\mathrm{SD}=7.6 \%)$ in Ottawa.

\section{Discussion}

\section{Contribution of bus commuting to daily TRAP exposures}

A range of fine-fraction elemental bus exposures were noted to be higher than ambient in all three cities, in particular $\mathrm{Al}$, $\mathrm{Ba}, \mathrm{Cu}, \mathrm{Fe}, \mathrm{Mn}$, and Ti. These elements are known to be related to non-exhaust emissions [24]. The concentrations of these elements were at least an order of magnitude greater in the bus environment relative to ambient. This resulted in the 66 minute bus commute ( $4.6 \%$ of the day) contributing the majority of daily exposures to these elemental concentrations. This was particularly the case for $\mathrm{Fe}$ and $\mathrm{Ba}$ where over $50 \%$ of daily exposure was estimated to originate from bus commuting in all three cities. These elements are expected to originate from brake wear as iron oxides and barium can constitute a large proportion of brake lining material [33]. The elemental composition of in-bus $\mathrm{PM}_{2.5}$ has also been studied in Barcelona, Spain where 48 samples were collected, each representing three 2-h monitoring sessions [34]. Elemental markers of brake dust were also found to be significantly higher than urban background. In contrast to this study, brake wear was represented by the elements $\mathrm{Sb}$ and $\mathrm{Cu}$. Fine-fraction concentrations of $\mathrm{Sb}$ and $\mathrm{Cu}$ were lower for routes with few gradients relative to routes with many. They were also notably lower in electrical buses relative to diesels which the authors attributed to the presence of regenerative braking in electric buses.

For the estimates of the contribution of bus commuting to daily UFP and BC exposure, commuting exposure was represented as a time-weighted average of waiting and riding exposures. This was an important measure on account of the significant difference of exposures noted between these two environments (Supplementary Table S4). In all three cities, UFP was higher in the waiting mode and BC levels were significantly different between the waiting and riding modes in Toronto and Vancouver. Bus commuting was estimated to constitute a fifth of daily BC exposure in each city in the 'low' ambient (non-commuting) scenario of $0.5 \mu \mathrm{g} / \mathrm{m}^{3}$. These estimates were lower than other studies which measured personal exposures throughout the day. In Australia, personal BC exposures were measured for one individual for twenty 24-h periods. Bus commuting was estimated to contribute $36 \%$ of daily exposure [35]. As well, the personal $\mathrm{BC}$ monitoring of 
26 individuals for 7 days estimated time spent in the "transport" activity to contribute $25.6 \%$ of daily BC exposure [36], however, the 'transport' activity included a variety of methods. Bus commuting was estimated to contribute less of daily UFP than BC. In the 'moderate' ambient (non-commuting) scenario of $10 \times 10^{3} \mathrm{pts} / \mathrm{cm}^{3}$, bus commuting contributed a mean of $7.1-8.9 \%$ of daily UFP exposure across the three cities. In two Canadian studies, mean indoor and outdoor UFP concentrations of $10 \times 10^{3} \mathrm{pts} / \mathrm{cm}^{3}$ were common. A study of 50 homes in Windsor found mean indoor levels of $10(\mathrm{SD}=27) \times 10^{3}$ $\mathrm{pts} / \mathrm{cm}^{3}$ in winter and $8(\mathrm{SD}=20) \times 10^{3} \mathrm{pts} / \mathrm{cm}^{3}$ in summer [37]. In Edmonton, 50 homes were also studied for one week in summer and winter where indoor UFPs were 10 $(\mathrm{SD}=25)$ in winter and $9(\mathrm{SD}=19)$ in summer [38]. Mean outdoor UFPs in both of these studies were also within $5-10 \times 10^{3} \mathrm{pts} / \mathrm{cm}^{3}$. The wide range of indoor and outdoor UFPs across homes measured in both of these studies suggest that there is considerable variation in the contribution of bus commuting to daily UFP, which is not reflected in our estimates.

\section{Bus stations as hotspots of exposure}

Bus stations in Toronto and Ottawa were estimated to have elevated concentrations of $\mathrm{BC}$ and $\mathrm{PM}_{2.5}$, relative to bus stops. Further, several bus stations were shown to be hotspots of BC exposures (Supplementary Figs. S9-S11) some of which exceeded a recent proposed 8-h occupational standard for elemental carbon $\left(5 \mu \mathrm{g} / \mathrm{m}^{3}\right)$ [39]. There was also evidence that elevated bus station levels could influence in-bus levels. In one example, the $\mathrm{PM}_{2.5}$, UFP, and $\mathrm{BC}$ concentrations of an enclosed bus station persisted in a bus for up to $20 \mathrm{~min}$ after it had left the station (Fig. 2). These in-bus exposures were also substantially higher than the ride that preceded it. This points to the potential for bus station air quality improvements to provide benefits to riding exposures as well.

\section{Impact of bus propulsion emission reduction systems on riding exposures}

Relative to the 1983-2003 diesel, the "2007- diesel" class featured lower in-bus BC exposures in all three systems as well as $\mathrm{PM}_{2.5}$ in Toronto and Vancouver and UFPs in Toronto. These lower $\mathrm{PM}_{2.5}$, UFP and $\mathrm{BC}$ levels are likely due to the use of DPFs. DPFs have been installed on most new heavy-duty diesel vehicles and buses since 2007 in order to comply with $\mathrm{PM}_{2.5}$ exhaust emission standards. Similarly, selective catalytic reduction (SCR) systems have been used since 2010 to meet the more stringent NOx exhaust emissions standards. DPFs have a significant effect on PM mass, especially the EC/BC/soot fractions compared to engines without them [40]. As buses in the "hybrid diesel/electric" class were all post-2006 make years, they also meet the same vehicle emissions standards as the "2007- diesel" class. Therefore, a comparison of the percent decreases in TRAP exposures between these two bus classes provides an indication of the potential for the hybrid diesel/electric technology to reduce in-bus exposures. The results of these comparisons revealed the same trend for each pollutant within each city, but differed between cities. In Ottawa, the exposure reductions for hybrid buses surpassed that of the "2007- diesel" class for each pollutant. In Vancouver, both of these bus types are similar in their percent reductions while in Toronto, the "2007- diesel' class" reductions surpassed that of the hybrid diesel class. Similar work examining the impact of bus fleet emission standards on in-bus TRAP exposures was also conducted in the bus rapid transit system of Bogotà, Columbia [41]. This research featured monitoring over 10 months of a year and
Table 5 Estimated reductions to mean waiting exposures with the simulation of station exposures being reduced to that of bus stops.

\begin{tabular}{lllll}
\hline Pollutant & City & \multicolumn{2}{c}{ Mean daily concentration (SD) } & $\begin{array}{l}\text { Mean \% reduction of } \\
\text { waiting exposures (SD) }\end{array}$ \\
\cline { 3 - 5 } & & Sampled data & $\begin{array}{l}\text { After the reduction of bus } \\
\text { station exposures to that of } \\
\text { bus stops }^{\mathrm{a}}\end{array}$ & \\
\hline $\mathrm{PM}_{2.5}\left(\mu \mathrm{gg} / \mathrm{m}^{3}\right)$ & Toronto & $27.5(14.2)$ & $24.3(13.6)$ & $13(7.5)$ \\
& Ottawa & $24.2(14.4)$ & $24.1(14.3)$ & $0.5(0.8)$ \\
& Vancouver & $15.2(5.6)$ & - & - \\
Ultrafine particles & Toronto & $23.5(8.1)$ & - & - \\
$\left(10^{3} \mathrm{pts} / \mathrm{cm}^{3}\right)$ & Ottawa & $26.8(15.7)$ & $23.6(13.6)$ & $11.4(2.6)$ \\
& Vancouver & $18.5(14.1)$ & - & $15.8(13.2)$ \\
$\mathrm{BC}\left(\mu \mathrm{g} / \mathrm{m}^{3}\right)$ & Toronto & $4.5(4.3)$ & $4.1(4.3)$ & $14.1(4.1)$ \\
& Ottawa & $2.9(1.6)$ & $2.5(1.3)$ & - \\
\hline
\end{tabular}

“-" denotes no evidence of higher stations exposures, relative to bus stops.

${ }^{a}$ Based on the percent increases of exposure for at outdoor and enclosed bus stations, relative to bus stops (Table 3). 
Table 6 Estimated reduction of overall bus riding exposures with replacement of 1983-2003 buses with hybrid diesel/ electric buses.

\begin{tabular}{llllc}
\hline Pollutant & City & \multicolumn{2}{c}{ Bus riding exposures (mean (SD)) } & $\begin{array}{l}\text { Estimated \% reduction of } \\
\text { riding exposures with fleet } \\
\text { changeover }\end{array}$ \\
\cline { 3 - 5 } & & Sampled fleet & $\begin{array}{l}\text { With replacement of } \\
1983-2003 \text { buses }\end{array}$ & $6.3(5.2)$ \\
\hline $\mathrm{PM}_{2.5}\left(\mu \mathrm{g} / \mathrm{m}^{3}\right)$ & Toronto & $22.5(9.9)$ & $21.3(9.9)$ & $6.6(4.8)$ \\
& Ottawa & $24.2(12.6)$ & $22.6(11.4)$ & $17.6(7.5)$ \\
& Vancouver & $18.2(5.5)$ & $15.0(4.8)$ & $3.6(3.1)$ \\
Ultrafine particles & Toronto & $15.8(4.4)$ & $15.2(4.3)$ & $10.7(7.6)$ \\
$\left(10^{3} \mathrm{pts} / \mathrm{cm}^{3}\right)$ & Ottawa & $18.3(8.6)$ & $16.7(8.6)$ & - \\
& Vancouver & $16(12.0)$ & - & $4.6(4.0)$ \\
$\mathrm{BC}\left(\mu \mathrm{g} / \mathrm{m}^{3}\right)$ & Toronto & $3.1(2.0)$ & $3.0(1.9)$ & $12.7(8.9)$ \\
& Ottawa & $2.6(1.5)$ & $2.1(1.1)$ & $9.9(4.1)$ \\
& Vancouver & $2.6(0.6)$ & $2.4(0.5)$ &
\end{tabular}

"-_" denotes no evidence of lower UFP exposures in diesel/electric hybrids relative to the 1983-2003 class. ${ }^{a}$ Based on estimates of $\%$ reduced exposure presented in Table 4.
Fig. 2 An example of the impact of elevated bus station exposures on riding exposures: a time series plot displaying the minutely $\mathrm{PM}_{2.5}$, UFPs, and $\mathrm{BC}$ concentrations of a bus ride to an enclosed bus station, a 12 minute waiting period at the enclosed bus station, and the subsequent ride.

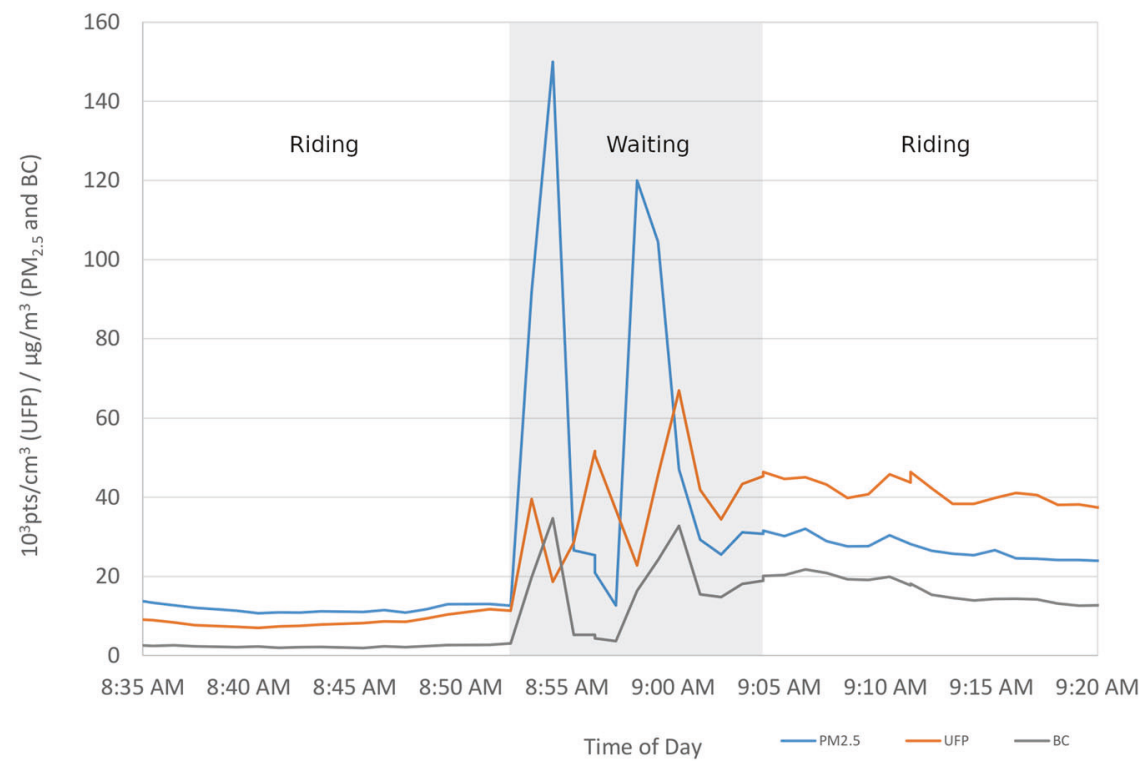

covered a large proportion of the bus transit network. Emission standards were also found to impact in-bus exposures. Buses with Euro II-III nominal emission standards were found to have significantly higher levels of $\mathrm{PM}_{2.5}$ and $\mathrm{BC}$ relative to Euro IV-V buses. However, the emissions standards of this bus fleet were older than those in our study. The Euro IV-V class roughly corresponds to post-2005 make years. This difference in the emission standards of this bus fleet was also reflected in significantly higher in-bus levels of $\mathrm{PM}_{2.5}($ mean $(\mathrm{SD})=176.3(137.8) \mu \mathrm{g} /$ $\left.\mathrm{m}^{3}\right)$ and $\mathrm{BC}\left(\mathrm{mean}(\mathrm{SD})=89.9(85.8) \mu \mathrm{g} / \mathrm{m}^{3}\right)$.

\section{Estimated impact of bus station air quality interventions}

Exposures at bus stations were associated with higher levels than bus stops, mainly for $\mathrm{PM}_{2.5}$ and $\mathrm{BC}$ in Toronto and
Ottawa. These associations were used to estimate the impact of air quality interventions at bus stations. We also found evidence that hybrid diesel/electric buses provided better air quality for their riders relative to 1983-2003 diesel buses. This finding was consistent for each city and continuously monitored pollutant $\left(\mathrm{PM}_{2.5}\right.$, UFP, and $\left.\mathrm{BC}\right)$ with the exception of UFPs in Vancouver. This suggests the potential for air quality improvements for bus riders with the replacement of 1983-2003 buses with that of hybrid diesel/ electric buses, and the reduction of bus station levels to that of bus stops. This potential was explored by estimating the impact of such changes on the exposures measured in this study. This analysis combined the effect size of these associations and the frequency with which the 1983-2003 buses and bus stations were encountered during sampling. The impact of bus fleet turnover was more extensive than reducing bus station exposures due to the magnitude of 
effect, consistency of this finding across cities and pollutants, and the frequency of encountering 1983-2003 buses. It is also likely that continued bus fleet renewal will contribute to better air quality in waiting environments as well.

\section{Comparison with UTES private vehicle and subway concentrations}

The UTES was designed to assess TRAP exposures in Canadian subway [18], private vehicle [19], and bus commuting environments. The predominant use of diesel propulsion in buses may result in higher exposure to diesel exhaust in buses, relative to private vehicles and subways. UTES investigated all three modes in both Toronto and Vancouver. In Toronto, subway UFPs were lowest (p50 $\left.(\mathrm{IQR})=9.1(6.2-12.4) \times 10^{3} \mathrm{pts} / \mathrm{cm}^{3}\right)$ where bus UFPs (summer $\mathrm{p} 50(\mathrm{IQR})=15.0(8.6-24.2) \times 10^{3} \mathrm{pts} / \mathrm{cm}^{3}$; winter $\left.\mathrm{p} 50(\mathrm{IQR})=17.3(10.7-27.7) \times 10^{3} \mathrm{pts} / \mathrm{cm}^{3}\right)$ were higher. However, private vehicle UFPs were highest (summer p50 $(\mathrm{IQR})=28.6(14.3-54.8) \times 10^{3} \mathrm{pts} / \mathrm{cm}^{3}$; winter $\mathrm{p} 50(\mathrm{IQR})=$ $\left.25.5(9.5-133.6) \times 10^{3} \mathrm{pts} / \mathrm{cm}^{3}\right)$. In Vancouver, this comparison of UFP levels revealed the same trend. Subway UFP were lowest $\left(\mathrm{p} 50(\mathrm{IQR})=7.0(3.8-18.3) \times 10^{3} \mathrm{pts} / \mathrm{cm}^{3}\right)$, followed by bus (summer p50(IQR) $=4.8(3.0-7.5) \times 10^{3} \mathrm{pts} /$ $\mathrm{cm}^{3}$; winter $\left.\mathrm{p} 50(\mathrm{IQR})=20.4(13.8-38.6) \times 10^{3} \mathrm{pts} / \mathrm{cm}^{3}\right)$ and then private vehicle $($ summer $\mathrm{p} 50(\mathrm{IQR})=20.6(2.8-57.9) \times$ $10^{3} \mathrm{pts} / \mathrm{cm}^{3}$; winter $\mathrm{p} 50(\mathrm{IQR})=30.9(9.6-66.8) \times 10^{3} \mathrm{pts} /$ $\mathrm{cm}^{3}$ ). For BC, the comparison of bus levels with that of the subway is not possible on account of subway BC measurements being highly influenced by iron oxides which can be prevalent in subway systems [42]. Toronto bus transit BC (summer p50(IQR) $=3.2(1.7-5.9) \mu \mathrm{g} / \mathrm{m}^{3}$; winter p50 $\left.(\mathrm{IQR})=1.1(0.6-2.1) \mu \mathrm{g} / \mathrm{m}^{3}\right)$ was similar to that of private vehicle (summer p50(IQR) $=1.9(0.3-6.9) \mu \mathrm{g} / \mathrm{m}^{3}$; winter $\left.\mathrm{p} 50(\mathrm{IQR})=1.1(0.5-1.9) \mu \mathrm{g} / \mathrm{m}^{3}\right)$. In Vancouver, the same trend was noted. Bus transit $\mathrm{BC}$ (summer $\mathrm{p} 50(\mathrm{IQR})=1.7$ $(1.0-2.9) \mu \mathrm{g} / \mathrm{m}^{3}$; winter $\left.\mathrm{p} 50(\mathrm{IQR})=1.8(1.1-3.1) \mu \mathrm{g} / \mathrm{m}^{3}\right)$ was similar to that of private vehicle $\mathrm{BC}$ (summer $\mathrm{p} 50(\mathrm{IQR})=1.8(1.6-5.9) \mu \mathrm{g} / \mathrm{m}^{3} ; \quad$ winter $\quad \mathrm{p} 50(\mathrm{IQR})=2.0$ $\left.(0.2-7.3) \mu \mathrm{g} / \mathrm{m}^{3}\right)$. These comparisons emphasize the distinct air pollution profile of subways and the relative similarity of bus and private vehicle environments.

\section{Conclusion}

In this paper we present concentrations for a wide variety of exhaust and non-exhaust traffic-related air pollutants for three Canadian bus transit systems. While the selection of bus routes did not employ statistical methods to ensure a representative sample, our sampling campaigns were extensive in both space and time. High ridership routes were selected which included the geographic extent of each bus network. As well, sampling was conducted during 15 summer and winter weekdays. Each day, three researchers concurrently sampled separate routes for three peak hours in the morning and evening. This equated to $540 \mathrm{~h}$ of sampling for each bus transit system. This dataset showed that bus commuting can contribute a high proportion of daily exposure to fine-fraction $\mathrm{Fe}$ and $\mathrm{Ba}$ as well as $\mathrm{BC}$. We also found riding exposures to be lower for hybrid diesel/electric buses relative to buses of 1983-2003 make years. Owing to the magnitude of these differences and the frequency of which the 1983-2003 class was encountered during sampling, the replacement of these buses with hybrid diesel/ electric buses was estimated to result in 4-18\% lower riding exposures across the eight combinations of city and pollutant where hybrid diesel/electric buses were found to have lower concentrations than the 1983-2003 class.

Our results also featured several indications that emphasized the capacity of buses to self-pollute. Frequent braking and accelerating at intersections and bus stops are typical of many bus routes and provide opportunities for a bus' own emissions to infiltrate into its cabin. In an analysis controlling for factors related to traffic, in-bus concentrations of several pollutants were found to be associated with bus type. This evidence suggests that a bus' own exhaust emissions have an independent effect on the exposures of its passengers. Non-exhaust emissions may also enter a bus' cabin more readily than exhaust emissions. While exhaust pipes were almost exclusively positioned on the roof at the rear of the buses, brake wear particles were emitted from each wheel. The high levels of the $\mathrm{Ba}$ and $\mathrm{Fe}$ brake markers in buses, relative to ambient, may also be an indicator of the capacity of buses to self-pollute [34].

In cities with limited subway systems, such as Ottawa, buses constitute the bulk of public transit infrastructure. In Toronto and Vancouver, bus transit networks are designed to complement the cross-city capacity of their extensive subway systems by providing transit from subway stations to stops within walking distance of of a majority of the city's homes. This can result in bus transit ridership figures exceeding that of a city's subway system. This is the case in Canada where the 2017 average weekday bus ridership exceeded that of the subway in Toronto $(1,406,800$ vs $877,300)$ and Vancouver $(789,400$ vs 472,100$)$ [43]. This emphasizes the status of buses as a staple of public transit. Ensuring clean air in their waiting and riding environments is key to their sustainability. Future research should focus on assessing the impact of newer emission control technologies. Several cities are working towards the goal of featuring soot-free bus fleets. Such investments have the potential to save money after a period of 5-9 years [44].

Acknowledgements The authors thank the Toronto Transit Commission, Ottawa's OC Transpo, and Vancouver's Coast Mountain Bus 
Company for their support. We also thank all field techncians, Hongyu You, and Dr. Eric Lavigne for their contribution to this study and the reviewers for their insightful comments.

\section{Compliance with ethical standards}

Conflict of interest This study was funded by Health Canada. We declare no conflicts of interest.

Publisher's note Springer Nature remains neutral with regard to jurisdictional claims in published maps and institutional affiliations.

Open Access This article is licensed under a Creative Commons Attribution 4.0 International License, which permits use, sharing, adaptation, distribution and reproduction in any medium or format, as long as you give appropriate credit to the original author(s) and the source, provide a link to the Creative Commons license, and indicate if changes were made. The images or other third party material in this article are included in the article's Creative Commons license, unless indicated otherwise in a credit line to the material. If material is not included in the article's Creative Commons license and your intended use is not permitted by statutory regulation or exceeds the permitted use, you will need to obtain permission directly from the copyright holder. To view a copy of this license, visit http://creativecommons. org/licenses/by/4.0/

\section{References}

1. Andersen ZJ, Hvidberg M, Jensen SS, Ketzel M, Loft S, Sorensen $\mathrm{M}$, et al. Chronic obstructive pulmonary disease and long-term exposure to traffic-related air pollution: a cohort study. Am J Respir Crit Care Med. 2011;183:455-61.

2. Gan WQ, Koehoorn M, Davies HW, Demers PA, Tamburic L, Brauer M. Long-term exposure to traffic-related air pollution and the risk of coronary heart disease hospitalization and mortality. Environ Health Perspect. 2011;119:501-7.

3. Chen H, Goldberg MS, Burnett RT, Jerrett M, Wheeler AJ, Villeneuve PJ. Long-term exposure to traffic-related air pollution and cardiovascular mortality. Epidemiology. 2013;24:35-43.

4. HEI Review Panel on Ultrafine Particles Understanding the Health Effects of Ambient Ultrafine Particles. HEI perspectives. 3rd ed. Boston, Massachusetts: Health Effects Institute; 2013.

5. Crouse DL, Goldberg MS, Ross NA, Chen H, Labreche F. Postmenopausal breast cancer is associated with exposure to traffic-related air pollution in Montreal, Canada: a case-control study. Environ Health Perspect. 2010;118:1578.

6. Parent ME, Goldberg MS, Crouse DL, Ross NA, Chen H, Valois MF, et al. Traffic-related air pollution and prostate cancer risk: a case-control study in Montreal, Canada. Occup Environ Med. 2013;70:511-8.

7. Hamra GB, Laden F, Cohen AJ, Raaschou-Nielsen O, Brauer M, Loomis D. Lung cancer and exposure to nitrogen dioxide and traffic: a systematic review and meta-analysis. Environ Health Perspect. 2015;123:1107-12.

8. Hystad P, Villeneuve PJ, Goldberg MS, Crouse DL, Johnson K, Canadian Cancer Registries Epidemiology Research Group. Exposure to traffic-related air pollution and the risk of developing breast cancer among women in eight Canadian provinces: a casecontrol study. Environ Int. 2015;74:240-8.

9. Krämer U, Herder C, Sugiri D, Strassburger K, Schikowski T, Ranft U, et al. Traffic-related air pollution and incident type 2 diabetes: results from the SALIA Cohort Study. Environ Health Perspect. 2010;118:1273-9.
10. Costa LG, Cole TB, Coburn J, Chang Y, Dao K, Roqué PJ. Neurotoxicity of traffic-related air pollution. NeuroToxicology. 2017;59:133-9.

11. Power MC, Weisskopf MG, Alexeeff SE, Coull BA, Spiro A, Schwartz J. Traffic-related air pollution and cognitive function in a cohort of older men. Environ Health Perspect. 2010;119:682-7.

12. Silva RA, Adelman Z, Fry MM, West JJ. The impact of individual anthropogenic emissions sectors on the global burden of human mortality due to ambient air pollution. Environ Health Perspect. 2016;124:1776-84.

13. Liu B, Frey HC. Variability in light-duty gasoline vehicle emission factors from trip-based real-world measurements. Environ Sci Technol. 2015;49:12525-34.

14. Stieb DM, Judek S, van Donkelaar A, Martin RV, Brand K, Shin $\mathrm{HH}$, et al. Estimated public health impacts of changes in concentrations of fine particle air pollution in Canada, 2000 to 2011. Can J Public Health. 2015;106:e362-8.

15. Matz C, Stieb D, Davis K, Egyed M, Rose A, Chou B, et al. Effects of age, season, gender and urban-rural status on timeactivity: Canadian Human Activity Pattern Survey 2 (CHAPS 2). Int J Environ Res Public Health. 2014;11:2108-24.

16. Dons E, Int Panis L, Van Poppel M, Theunis J, Wets G. Personal exposure to Black Carbon in transport microenvironments. Atmos Environ. 2012;55:392-8.

17. Nieuwenhuijsen MJ, Donaire-Gonzalez D, Rivas I, de Castro M, Cirach M, Hoek G, et al. Variability in and agreement between modeled and personal continuously measured black carbon levels using novel smartphone and sensor technologies. Environ Sci Technol. 2015;49:2977-82.

18. Van Ryswyk K, Anastasopolos AT, Evans G, Sun L, Sabaliauskas $\mathrm{K}$, Kulka R, et al. Metro commuter exposures to particulate air pollution and PM2.5-associated elements in Three Canadian Cities: the urban transportation exposure study. Environ Sci Technol. 2017;51:5713-20.

19. Weichenthal S, Van Ryswyk K, Kulka R, Sun L, Wallace L, Joseph L. In-vehicle exposures to particulate air pollution in Canadian metropolitan areas: the urban transportation exposure study. Environ Sci Technol. 2015;49:597-05.

20. Matz CJ, Stieb DM, Egyed M, Brion O, Johnson M. Evaluation of daily time spent in transportation and traffic-influenced microenvironments by urban Canadians. Air Qual Atmos Health. 2018;11:209-20.

21. IARC Working Group on the Evaluation of Carcinogenic Risks to Humans. Diesel and gasoline engine exhaust and some nitroarenes-IARC monographs on the evaluation of carcinogenic risks to humans. 2012, 105.

22. Janssen NAH, Gerlofs-Nijland ME, Lanki T, Salonen RO, Cassee F, Hoek G, et al. Health effects of black carbon. Copenhagen: World Health Organization; 2012.

23. Stafoggia M, Faustini A. Impact on public health-epidemiological studies: a review of epidemiological studies on non-exhaust particles: identification of gaps and future needs. 2018, 67-88.

24. Evans GJ, Audette C, Badali K, Celo V, Dabek-Zlotorszynka E, Debosz J, et al. Near-road air pollution pilot study final report. Toronto, Ontario, Canada: Southern Ontario Centre for Atmospheric Aerosol Research, University of Toronto; 2019.

25. Pant $P$, Harrison RM. Estimation of the contribution of road traffic emissions to particulate matter concentrations from field measurements: a review. Atmos Environ. 2013;77:78-97.

26. Basagaa X, Jacquemin B, Karanasiou A, Ostro B, Querol X, Agis $\mathrm{D}$, et al. Short-term effects of particulate matter constituents on daily hospitalizations and mortality in five South-European cities: results from the MED-PARTICLES project. Environ Int. 2015;75:151-8.

27. Bell ML, Ebisu K, Leaderer BP, Gent JF, Lee HJ, Koutrakis P, et al. Associations of $\mathrm{PM}_{2.5}$ constituents and sources with hospital 
admissions: analysis of four counties in connecticut and Massachusetts (USA) for persons $\geq 65$ years of age. Environ Health Perspect. 2014;122:138-44.

28. Cakmak S, Dales R, Kauri LM, Mahmud M, Van Ryswyk K, Vanos J, et al. Metal composition of fine particulate air pollution and acute changes in cardiorespiratory physiology. Environ Pollut. 2014;189:208-14.

29. Raaschou-Nielsen O, Beelen R, Wang M, Hoek G, Andersen ZJ, Hoffmann B, et al. Particulate matter air pollution components and risk for lung cancer. Environ Int. 2016;87:66-73.

30. Wheeler AJ, Xu X, Kulka R, You H, Wallace L, Mallach G, et al. Windsor, Ontario exposure assessment study: design and methods validation of personal, indoor, and outdoor air pollution monitoring. J Air Waste Manag Assoc. 2011;61:142-56.

31. Hess DB, Ray PD, Stinson AE, Park J. Determinants of exposure to fine particulate matter (PM2.5) for waiting passengers at bus stops. Atmos Environ. 2010;44:5174-82.

32. Wu D, Lin M, Chan C, Li W, Tao J, Li Y, et al. Influences of commuting mode, air conditioning mode and meteorological parameters on fine particle $\left(\mathrm{PM}_{2.5}\right)$ exposure levels in traffic microenvironments. Aerosol Air Qual Res. 2013;13:709-20.

33. Grigoratos T, Martini G. Brake wear particle emissions: a review. Environ Sci Pollut Res. 2015;22:2491-504.

34. Fernández-Iriarte A, Amato F, Moreno N, Pacitto A, Reche C, Marco E, et al. Chemistry and sources of PM2.5 and volatile organic compounds breathed inside urban commuting and tourist buses. Atmos Environ. 2020;223:117234.

35. Williams RD, Knibbs LD. Daily personal exposure to black carbon: a pilot study. Atmos Environ. 2016;132:296-9.
36. Dons E, Int Panis L, Van Poppel M, Theunis J, Willems H, Torfs $\mathrm{R}$, et al. Impact of time-activity patterns on personal exposure to black carbon. Atmos Environ. 2011;45:3594-602.

37. Kearney J, Wallace L, MacNeill M, Xu X, VanRyswyk K, You H, et al. Residential indoor and outdoor ultrafine particles in Windsor, Ontario. Atmos Environ. 2011;45:7583-93.

38. Kearney J, Wallace L, MacNeill M, Héroux M, Kindzierski W, Wheeler A. Residential infiltration of fine and ultrafine particles in Edmonton. Atmos Environ. 2014;94:793-805.

39. Cancer Care Ontario. Occupational Cancer Research CentreBurden of Occupational Cancer in Ontario: Major workplace carcinogens and prevention of exposure. Toronto: Queen's Printer for Ontario; 2017.

40. Khalek IA, Bougher TL, Merritt PM, Zielinska B. Regulated and unregulated emissions from highway heavy-duty diesel engines complying with U.S. Environmental Protection Agency 2007 emissions standards. J Air Waste Manag Assoc. 2011;61:427-42.

41. Morales Betancourt R, Galvis B, Rincón-Riveros JM, RincónCaro MA, Rodriguez-Valencia A, Sarmiento OL. Personal exposure to air pollutants in a Bus Rapid Transit System: Impact of fleet age and emission standard. Atmos Environ. 2019;202:117-27.

42. Moreno T, Martins V, Reche C, Minguillón MC, de Miguel E, Querol X. Air quality in subway systems. 2018, 289-321.

43. American Public Transportation Association Ridership Report Archives. 2018. http://www.apta.com/resources/statistics/Pages/ RidershipArchives.aspx.

44. Miller J, Minjares R, Dallmann TR, Jin L. Financing the transition to soot-free urban bus fleets in 20 megacities. 2017, 1-49. 